\title{
Entrepreneurial cognition, sustainability and venture performance: a machine learning approach
}

\author{
Vuorio Anna, Puumalainen Kaisu
}

This is a Author's accepted manuscript (AAM) version of a publication

published by Edward Elgar Publishing

in Sustainable Entrepreneurship and Entrepreneurial Ecosystems : Frontiers in European Entrepreneurship Research

DOI: $10.4337 / 9781839109690.00009$

Copyright of the original publication: (c) Editors 2020

Please cite the publication as follows:

Vuorio, A., \& Puumalainen, K. (2020). "Entrepreneurial cognition, sustainability and venture performance: a machine learning approach". In Sustainable Entrepreneurship and Entrepreneurial Ecosystems. Cheltenham, UK: Edward Elgar Publishing. doi: https://doi. org/10.4337/9781839109690.00009

This is a draft chapter. The final version is available in Sustainable Entrepreneurship and Entrepreneurial Ecosystems edited by Eddy Laveren, Robert Blackburn, Cyrine Ben-Hafaiedh et. al., published in 2020, Edward Elgar Publishing Ltd.

http://dx.doi.org/10.4337/9781839109690.00009

The material cannot be used for any other purpose without further permission of the publisher, and is for private use only.

This is a parallel published version of an original publication. This version can differ from the original published article. 


\begin{abstract}
Entrepreneurial process centers on decision-making and action in a context that is characterized as highly uncertain (McMullen and Shepherd, 2006). Effectuation and causation are two complimentary decision-making logics, through which entrepreneurs recognize and exploit entrepreneurial opportunities (Sarasvathy, 2001). Sustainable entrepreneurs aim to balance three types of value, namely social, environmental and economic value, due to their conflicting nature (Hahn et al., 2010; Munoz and Cohen, 2018). By so far, there have limited evidence about the circumstances, under which conditions effectuation and causation generate gains and losses, especially in the context of sustainable entrepreneurship. This study addresses this question by applying machine learning approach, namely artificial neural network, to analyze 301 Finnish SMEs from multiple industries. The results of the analysis suggest three distinctive mindsets combining value creation potential perceptions and decision-making logics. These results contribute both the entrepreneurial decision-making and sustainable entrepreneurship research.
\end{abstract}

KEYWORDS: entrepreneurial decision-making, effectuation, causation, sustainable entrepreneurship, machine learning, value creation 
ENTREPRENEURIAL COGNITION, SUSTAINABILITY AND VENTURE PERFORMANCE: A MACHINE LEARNING APPROACH

\section{INTRODUCTION}

Decision-making and action in a highly uncertain context are at the center of the entrepreneurial process (Sarasvathy, 2001; McMullen and Shepherd, 2006). Although action characterizes the entrepreneurial process, it is often preceded by decision-making (Lerner et al., 2018). Two complimentary decision-making logics, causation and effectuation, have been recognized in the prior literature to describe how entrepreneurs make decisions leading to opportunity recognition and exploitation (Sarasvathy, 2001). Regardless of the substantial amount of research on decision-making logics, effectuation theory and the concept of effectuation still need further development (Arend et al., 2015; Read et al., 2016). Especially conditions under which effectuation and causation are applied and the type of benefits and disadvantages they generate under specific conditions need further examination (Sarasvathy, 2001; Read et al., 2016). Recently, some results (e.g. Jiang and Tornikoski, 2019; Welter and Kim, 2018) have been provided about the context in which entrepreneurs use the two different decision-making logics. However, to the best of our knowledge, it seems that the research on conditions for effectuation and causation has tended to focus on uncertainty and accuracy of prediction. In the contemporary economies, in which the pace of change and complexity are high, alternative approaches that rely on experimentation and provide flexibility are needed to generate diversity through entrepreneurial actions (Arend et al., 2015).

Sustainable entrepreneurship is a particular form of entrepreneurship, through which three types of value, social, environmental and economic value to an entrepreneur and others, are created (Patzelt and Shepherd, 2011; Schaltegger and Wagner, 2011; Shepherd and Patzelt, 2011). The focus on three types of value is the factor, which makes sustainable entrepreneurs different from other types of entrepreneurs (Patzelt and Shepherd, 2010; Schaltegger and Wagner, 2011). Despite the decade of research, there is still a lack of understanding of how sustainable enterprises come into existence (Munoz and Dimov, 2015; Munoz and Cohen, 2018). Furthermore, the assumption about balancing three types of value has been found to be problematic, since these values seem to be conflicting (Hahn et al., 2010; Munoz and Cohen, 2018). Instead, sustainable ventures have a step-by-step approach to developing value creation goals, rather than trying to manage all three types of goals at once (Belz and Binder, 2017). Aiming to balance the three types of value associated with sustainability has been argued to constrain a company's willingness to fundamentally change core business practices and rather settle for solutions that do not radically change business practices (Hahn et al. 2010).

Since sustainable entrepreneurship centers on three types of value creation potentials, these value potentials should also characterize potential entrepreneurial opportunities. However, there is only limited evidence about the attributes of potential entrepreneurial opportunities that include sustainable value creation. Furthermore, although decision-making logics have gained considerable attention in the entrepreneurship literature (e.g. Chandler et al., 2011; Smolka et al., 2016; Jiang and Tornikoski, 2019; Welter and Kim, 2018), there seems to be lack of studies that focus on decision-making in sustainable entrepreneurship (Muñoz, 2018). Additionally, there is only limited evidence about entrepreneurial opportunity recognition (e.g. Hanohov and Baldacchino, 2018) in sustainable entrepreneurship and the literature seems to focus on factors that shape sustainable entrepreneurial opportunity recognition rather than dimensions of a perceived potential entrepreneurial opportunity. 
This chapter thus attempts to shed light on how decision-making logics and perceptions of entrepreneurial opportunities shape venture performance. Although the impact of being sustainable has been studied in the prior literature, it remains unclear how perceptions of opportunities together with decision-making logics influence performance outcomes. Findings of the prior literature on impacts of effectuation and causation have been mixed and there is only limited evidence how the two logics may be utilized in the context of sustainability incentives (e.g. Grimm and Amatucci, 2013). Furthermore, Muñoz and Cohen (2018) have put forward a call on an alternative methodological approach to study sustainable entrepreneurship and this chapter thus applies a machine learning approach.

The results of the study provide new insights by extending findings of the prior literature about the conditions under which effectuation and causation provide benefits and disadvantages. Second, the results extend our understanding of a connection between effectuation and causation. Third, the results provide new light on the decision-making in the context of potential sustainable entrepreneurial opportunities by including three types of value creation potentials. Lastly, a methodological approach that has been less conventional in entrepreneurship research is applied.

\section{OPPORTUNITY RECOGNITION AS A COGNITIVE PROCESS}

Entrepreneurial opportunity recognition, which is the first step towards entrepreneurial action, occurs through two cognitive processes: signal and pattern detection. Opportunity recognition is a cognitive process, in which external market signals are interpreted through mental filters, through which an image of a potential entrepreneurial opportunity is formed (Renko et al., 2012). According to Baron and Ward (2004, p. 558), "perhaps opportunities come into existence in the external world as a result of unrelated changes in technology, markets, demographics, and government policies or regulations; however, they remain merely a potential until one or more persons "connects the dots" and perceives a pattern among them". Discrete external changes may only be considered as potential entrepreneurial opportunities when an individual or a group of individuals perceive a pattern among them. As a result, identifying a pattern of dispersed external changes resulting from subjective interpretation is described by recognition of a potential entrepreneurial opportunity.

According to signal detection theory when an individual is attempting to define whether a signal exists or not, four different scenarios are present: correct identification, miss, false alarm and correct rejection (Baron, 2004). Correct identification occurs when a signal exists and an individual perceives it, while the false alarm is a situation, in which an individual perceives a signal, although the signal does not exist. Similarly, a miss occurs when an individual does not perceive a signal, although it exists, and correct rejection is a situation, in which a signal does not exist and individual does not perceive it. Thus, two types of signals, "real" signals and false signals, and two distinct signal-processing mechanisms, recognition and blocking, can be identified (Baron, 2004). However, perceiving different market signals is not enough; an individual to recognize a potential entrepreneurial opportunity, one must perceive a pattern among these signals. According to the pattern detection theory, individuals utilize experiencebased cognitive frameworks to make decisions about connections between multiple discrete external signals (Baron, 2006). Individuals thus notice patterns among separate external events. This means that emergence of entrepreneurial opportunities requires that individuals recognize connections between changes in the surrounding environment, including technological, political, demographic or market development (Baron, 2006; Baron and Ward, 2004). 
A key to entrepreneurial opportunity recognition is cognitive frameworks in the form of mental models (Barreto, 2012; Renko et al., 2012). These mental models are knowledge filters that process actual market signals, and as a result of this process, perceptions of a potential entrepreneurial opportunity are formed (Renko et al., 2012). Potential entrepreneurial opportunities thus are recognized by utilizing knowledge structures that act as perceptual filters to notice and interpret different market signals (Barreto, 2012; Renko et al., 2012). A match or a mismatch between perceptual filters and signals determine which signals are processed and blocked. In other words, decisions whether something is perceived as a potential entrepreneurial opportunity or not are made based on these perceptual filters, which build on the prior experience.

There is only limited evidence about the characteristics of potential entrepreneurial opportunities or new venture ideas (Davidsson, 2019), which in this study are seen as the same phenomenon. The prior literature has included following characteristics to describe entrepreneurial opportunities: novelty, economic value potential, growth and riskiness (e.g. Baron and Ensley 2006; Haynie et al. 2006; Gruber et al. 2015; Santos et al. 2015). Out of these characteristics, innovativeness/novelty, economic value potential and riskiness/uncertainty are inherently related to entrepreneurship. Despite the emergence of sustainable entrepreneurship, alternative value creation beyond economic value has not been included as a dimension of a potential entrepreneurial opportunity (with the exceptions of Shepherd et al. 2013). Simultaneously, entrepreneurship has been proposed as one way to alleviate poverty and others' suffering (Patzelt and Shepherd, 2011; Sutter et al., 2019). Alternative value creation potentials (social, environmental and sustainable value) thus should be included as a dimension of a potential entrepreneurial opportunity.

\section{DECISION-MAKING LOGICS}

Decision-making logics describe individual strategies towards opportunity recognition, development and exploitation. The prior literature has approach new venture creation from the perspective of two decision-making logics, causation and effectuation (Sarascathy, 2001). Causation has been connected to planning; while effectuation is associated with controlling (Sarasvathy, 2001; Smolka et al., 2018). More precisely, causation is connected to predefined goals, competitive analysis, business planning, expected return maximization, capabilities and resources, while effectuation focuses on developing goals, environmental contingencies, precommitment, affordable loss and alliances (Chandler et al., 2011; Brettel et al., 2012).

Four key elements differentiate effectuation from causation (Sarasvathy, 2001). First, causation logic focuses on a particular goal as bases for action and centers on gathering the needed resources to achieve that goal (Sarasvathy, 2001; Reymen et al., 2015). The starting point of venture creation thus under causation logic is setting a specific goal (Reymen et al., 2015). Conversely, effectuation logic focuses on an individual's means (knowledge, resources, capabilities and social capital) and explores what kind of possible effects may be generated by combining those means (Sarasvathy, 2001; Reymen et al., 2015). Second, effectual decisionmaking relies on how much individuals are able to lose, and as a result, individuals using effectual logic tend to prefer those options that generate more options in the future. Conversely, decision-making under causation bases on expected returns and thus those options that generate the largest possible returns from the decision-making are preferred. Third, while causation focuses on analyzing competition in the market, effectuation relies on building alliances and pre-commitments to tackle uncertainty (Sarasvathy, 2001). Closing and protecting oneself from the competition is connected to causation, while effectuation is focusing more on 
coopetition. Fourth, effectuation acknowledges that the future is unpredictable and thus the focus should be on those aspects that are controllable (Sarasvathy, 2001). As a result, effectual decision-making enables an entrepreneur to exploit events and conditions through flexibility (Chandler et al., 2011). Conversely, decision-making under causation associates unexpected events as interruptions to the current plan to achieve a particular goal and thus an ability to predict and controllability of the future go hand in hand (Sarasvathy, 2001; Reymen et al., 2015). The two decision-making logics thus differ in a fundamental way in terms of outcome and way to achieve it: under causation, the focus is on what is needed to create a particular effect, while effectuation centers on which kind of effect can be created with existing resources, capabilities and relationships.

Although these two decision-making logics are opposites, they are not substitutes for one another. For example, the prior research has found that causation together with experimentation has a positive impact on venture performance (Smolka et al., 2018). When experimentation is high, the impact of causation on venture performance is higher than when experimentation is low. Furthermore, similar results about the connection between effectuation and causation have been provided by (Jiang and Tornikoski, 2019), though they show that context matters.

Mental Models, Decision-Making and Performance Implications

The entrepreneurial decision-making process is connected to venture performance. However, results regarding the influence that causation and effectuation have on venture performance are mixed. First, a positive effect of planning on performance has been found; however, this relationship is contingent on the age of a company and cultural context (Brinckmann et al., 2010). According to the results established small companies gain more from planning than new ventures and benefits from planning lower in a cultural context with higher uncertainty avoidance compared to lower uncertainty avoidance. Furthermore, causation has been connected to venture viability (Greene and Hopp, 2017) and financial performance (Roach et al., 2016). Conversely, effectuation has been found to provide positive search performance outcomes over causation (Welter and Kim, 2018) and different elements of effectuation have been found to enhance financial performance, sales growth and cash flow, time of the first sale and profit (McKelvie et al., 2013). Additionally, a connection between causation and effectuation has been found (Smolka et al., 2018) suggesting that these two decision-making logics may be complimentary.

Entrepreneurial decision-making always is context-specific. Being essential to human reasoning, effectuation and causation are associated with different decision-making contexts and actions and thus they may be intertwined, overlapping and occur simultaneously (Sarasvathy, 2001). More recently, it has been proposed that effectuation could be beneficial under most conditions. However applying both decision-making logics simultaneously, rather than separately, would seem likely to generate better results (Reymen et al., 2015; Welter and Kim, 2018). Sarasvathy (2001) proposed that effectuation is associated with uncertain contexts, while causation relates to risky contexts. Moreover, regardless the type of uncertainty, effectuation becomes more prominent, when uncertainty is present during the first phases of starting a venture, while when uncertainty is absent; the entrepreneurs seem to rely on causation (Jiang and Tornikoski, 2019). On the other hand, the findings of Welter and Kim (2018) show that effectuation provider better performance outcomes under both uncertainty and risks. Beyond uncertainty, the use of the two decision-making logics has been shown to depend 
on the degree of innovativeness of a research and development project (Brettel et al., 2012) The results show that in the context of high innovativeness, affordable loss and acknowledged unexpected enhance process efficiency and project outcome. Conversely, in the context of low innovativeness most elements of causation had a positive impact on process efficiency and project outcome. This suggests that the degree of novelty/innovativeness may play a role in the use of decision-making logics. Additionally, such context-specific factors as the number of resources available and the amount of external pressure have been proposed to influence the chosen decision-making logic through changes in venture scoping decisions (Reymen et al., 2015). However, these do not particularly relate to the perceived dimensions of potential entrepreneurial opportunity.

Decision-making involving sustainability is contextual, includes balancing values and tends to focus on social actions (Martin, 2015). Furthermore, to create sustainable value through making sustainable decisions, a complex balance between cognitive factors is needed, since three types of objectives (economic, social and environmental) are combined in these decisions (Muñoz and Dimov, 2015). The prior social entrepreneurship literature has shown that the combination of effectuation and causation are present in the entrepreneurial opportunity development (Corner and Ho, 2010). This implies that there might be some context-specific difference in the use of causation and effectuation depending on the type of perceived value creation potential. However, it remains unclear whether or not being sustainable is beneficial for companies. The connection between corporate social responsibility (CSR) activities have been found to enhance and limit financial performance (Wang and Bansal, 2012; Dixon-Fowler et al., 2013, but the relationship between CSR activities and financial performance has been found to be positively moderated by long-term orientation (Wang and Bansal, 2012). This implies that new ventures that have a long-term plan for sustainable business practices tend to generate positive results from those activities. Additionally, small firms seem to generate more benefits from CSR activities that larger firms (Dixon-Fowler et al., 2013).

\section{METHODOLOGY}

A representative sample ( $\mathrm{N}=301)$ of Finnish SMEs was collected via a survey in 2017 . The survey was targeted at owner-managers of Finnish SMEs, who preferably also had been involved in establishing the firm themselves. Three target regions were selected: the capital, the southeast (low entrepreneurship rate) and Ostrobothnia (high entrepreneurship rate) region. To capture variability in perceptions of entrepreneurial opportunities, several (37) ISIC two-digit level industry categories were selected, among them manufacturing, water and waste management, electricity, trade, construction, business services, hospitality, information and social services. The aim of the multiple industries was to include different types of businesses and entrepreneurs, who have varying perceptions of entrepreneurial opportunities in order to capture diversity in entrepreneurial opportunities. Additionally, the firms included had to fulfill the following criteria: firms were young (three to five years old) and micro-, small- and medium-sized (5-250 employees) or 2) firms were older (over five years old) and small-and medium-sized (10250 employees). Through the above criteria, the aim was to reach firms, whose direction for the company was already established and who had grown at different pace since their founding.

The survey was executed via computer-aided telephone interviews by a large market research company. A stratified sample contains 2386 companies from the Bisnode company register, which covers all Finnish enterprises, out of which 1625 firms (68 percent of the sample) were contacted. Out of the contacted firms, 301 responded to the survey, resulting in a 
response rate of 18.5 percent, which can be considered satisfactory given the length of the survey. Out of those 301 individuals, 204 either had by themselves or together with others found the firm. The average age of the enterprises is 12 , while the average age of the respondents is 51 and 73 percent of the respondents are male. Over half of the respondents have an entrepreneurial background, and the average respondent has over 17 years of entrepreneurial experience. Additionally, the average respondent has over 23 years of industry-specific experience.

The survey contained measurements scales adopted from the literature and one selfdeveloped scale for entrepreneurial opportunity perceptions. The self developed scale is derived from the prior entrepreneurship literature and covers the following dimensions: economic, social and environmental value potential (e.g. Baron and Ensley 2006; Haynie et al. 2009; Shepherd and Patzelt, 2011), novelty (Haynie et al., 2009; Santos et al., 2015) and uncertainty (Baron and Ensley, 2006; Haynie et al., 2009; Gruber et al., 2015). Economic value potential consists of four items describing the value potential for the entrepreneur and in general. Sustainable value potential includes six items covering social and environmental value creation potential to society and its importance to the entrepreneur. Novelty comprises of three items that focus on novelty in general and the degree of novelty, while uncertainty includes three items covering uncertainty caused by financial investment, risk of failure and time pressure. Decision-making logic was measured utilizing the scale developed by Chandler et al. (2011). Apart from causation, effectuation comprises of four dimensions: experimentation, affordable loss, flexibility and precommitments/alliances. Lastly, profitability was measured by asking the respondents to rate their companies' performance during the past few years relative to their closest competitors. The measure was dichotomized into three categories, higher, the same, lower performance compared to competitors. The variables were composed based on factor analyses. The results show that the variables seem reliable, since the Cronbach's alphas are above 0.6, except for uncertainty. Descriptive analysis is presented below in the Table 4.1.

\section{$<$ INSERT TABLE 4.1. ABOUT HERE}

\section{Machine learning methods}

The data was analyzed using artificial neural networks (ANN), which is inspired by the nervous system. ANN is a semi-parametric or non-parametric model, which means that coefficients cannot be used in a similar manner as e.g. logistic regression (Dreiseitl and Ohno-Machado, 2002). ANN is used to model complex and nonlinear relationships between attribute set $\boldsymbol{X}$ and the outcome (Kotu and Despande, 2015). It aims to create predictions by utilizing backpropagation to learn the relationship between an attribute set and an outcome. This is accomplished by using hidden layers and multiple nodes inside the hidden layer. $\boldsymbol{X}$ can be described as follows:

$$
\boldsymbol{X}=\left\{X_{1}, X_{2}, X_{3}, \ldots, X_{n}\right\}
$$

Information about the attribute set is assigned to nodes inside the hidden layer by using weights. It can be described as a linear function between the inputs and hidden layer as well as 
the hidden layer and the outputs (Dreiseitl and Ohno-Machado, 2002). The ANN Model used in the study is presented below in Figure 4.1.

\section{<INSERT FIGURE 4.1 ABOUT HERE}

The use of a hidden layer in the model transforms the model into a nonlinear one since there is no linear relationship between inputs and outputs (Dreiseitl and Ohno-Machado, 2002). Furthermore, the ANN model's weights are optimized using maximum likelihood estimation. ANN models are flexible, which may create overfitting. The flexibility can be increased by adding hidden layers and hidden nodes.

\section{RESULTS}

An ANN model was applied in order to examine connections between input and output variables. We used cross-validation to strengthen the reliability of the models. The sample was randomly divided into ten folds in a way that each fold contained a training set and test set. Cross-validation was used to define the optimal number of hidden nodes in the hidden layer. Generally, one hidden layer is adequate for the most data sets, which was also the case here. A training set was used to train the model, which predicted the outcomes in a test set. The results show that ANN model (one hidden layer, three nodes) is able to predict 44.63 percent of the outcomes correctly (accuracy). The confidence level in the model is 7.77 percent, suggesting that the accuracy between ten alternative solutions generated during ANN vary between 36.86 and 52.40 percent. Furthermore, class recall varies between 57.58 and 11.54 percent and class precision is between 51.35 and 27.27 percent. This suggests that the model is able to predict correctly 57.6 percent of those, whose subjective financial performance is better than competitors' performance, while it was able to predict correctly 11.5 percent of those, whose subjective financial performance is worse than competitors' performance. In order for the model to be better than a random model, accuracy, recall and precision should be over 33.3 percent. This applies to the ANN model for the most parts; however, the model does not meet this criterion for class recall and precision, when predicting those who perceive their venture to perform worse than their competitors do. The ANN typology describing the connection between decision-making logics, dimensions of opportunity perceptions and perceived venture performance is presented below in Table 5.1.

\section{$<$ INSERT TABLE 5.1 ABOUT HERE}

First, the effect of each input layer factor on the hidden layer was examined. The results of the ANN analysis show that the last factor of the input layer (the degree of uncertainty) has the highest total contribution of 9.527 to the three hidden nodes constituting the hidden layer. The second highest contribution is generated by the degree of novelty (7.754), which is closely followed by causation with the total contribution of 7.304 on the three hidden nodes. The lowest total contribution of 4.880 to the hidden layer nodes is created by flexibility. Conversely, most of the elements of effectuation and the degree of sustainable value potential act as inhibitors, 
having a negative effect on the hidden layer. The highest inhibitory effect of -10.162 is generated by experimentation and the second-highest inhibitory effect is shown by affordable loss (-8.328). The lowest inhibitory effect of -1.958 is generated by pre-commitments and alliances.

Experimentation (1.392), as well as the degree of novelty (3.892), economic value potential (2.425) and uncertainty (11.529) of an opportunity, contribute to the first node, and thus the node 1 is labeled experimenter mindset. Conversely, causation, the other elements of effectuation and the degree of sustainable value potential contribute negatively to the hidden layer node, having an inhibitory effect on the node. The largest negative weight of -7.891 on the node is generated by affordable loss, followed by the degree of sustainable value potential (4.875). This suggests that when a perceived opportunity is high in uncertainty, novelty and economic value potential, and low in sustainable value potential, this type of opportunity perception is connected with experimentation. Furthermore, the results imply that perceived opportunities characterized by high uncertainty may direct entrepreneurs experiment more since there is so much unknown that experimentation is the only way to approach the opportunity. Conversely, considering how much a person can afford to lose and a more planning oriented approach may not be beneficial in the case of perceived opportunities that are characterized by uncertainty and novelty.

The second node is labeled flexible planner mindset since its contributory weight is derived from causation (5.594), affordable loss (3.765), flexibility (4.845), and the degree of novelty (5.671), sustainable value potential (2.054) and uncertainty (2.916) of an opportunity. Other elements of effectuation and the degree of the economic value potential have an inhibitory effect on the node (negative weight). The highest negative effect of -6.111 is generated by the degree of the economic value potential of an opportunity, followed by experimentation (-5.315). This suggests that perceived opportunities that are novel, uncertain and enable sustainable value creation are associated with planning and consideration of how much a person can lose combined with flexibility. Conversely, free experimentation may not provide benefits, when combined with this type of perceived opportunity.

Causation (4.638), flexibility (0.420), pre-commitments and alliances (3.094), and the degree of economic value potential (8.618) contribute to the third node of the hidden layer and thus the third node is labeled networking planner mindset. Conversely, experimentation, affordable loss and the degree of novelty, sustainable value potential and uncertainty have an inhibitory effect on the node and thus contributing negatively to the node. The highest inhibitory effect of -6.239 is generated by experimentation, which is followed by the degree of uncertainty (-4.918). These results suggest that when the perception of an opportunity focuses on economic value potential, it seem that planning and utilizing personal networks may be a beneficial strategy, while experimenting and thinking how much one can afford to lose may not generate benefits.

Second, the impact of the hidden layer nodes on the output layer was examined. The output variable contained three categories, better, the same and worse profitability than competitors. The weights of each hidden layer node on the outcome level node are shown in Table 5.1. The results show that both flexible planner mindset (node 2) and networking planner mindset (node 3) contribute to the perception of better performance compared to competitors' performance (output node 2). The highest contributory weight of 5.045 is generated by networking planner mindset, while the effect of 2.012 is shown by flexible planner mindset. Experimenter mindset (node 1) has an inhibitory effect (albeit marginal less than 1.0) of -0.816 on the perceived higher performance than competitors have. Conversely, none of the hidden 
layer nodes have a contributory effect on the perceived similar level of performance with competitors. However, experimenter mindset contributes to the perception of worse performance compared to competitors' performance with the weight of 5.419 (output node 3). On the other hand, flexible planner mindset (node 2) and networking planner mindset (node 3) show inhibitory effect on the perception of worse performance compared to competitors' performance (output node 3). Taken these results together, it seems that having a plan and utilizing ones social capital under specific circumstances may provide performance benefits, while not having a specific plan under the context of high uncertainty seems to generate undesirable performance implications.

\section{DISCUSSION AND CONCLUSIONS}

The goal of the study was to provide new insights on how decision-making logics and perceptions of entrepreneurial opportunities shape the venture performance. The recent results of the prior literature on effectuation and causation have provided some insights about the conditional differences related to uncertainty, under which these two logics have been utilized during the venture creation process (Yiang and Tornikoski, 2018). However, there is still only limited understanding under which conditions effectuation and causation provide benefits and disadvantages, a call put forward by Sarasvathy (2001). By examining data collected from Finnish owner-entrepreneurs via machine learning method, the contribution of the paper is threefold. The findings of the study provide new understanding about 1) the use of two different decision-making logics, 2) conditions under which those decision-making logics are used and 3) the performance implications of the logics combined with certain conditions.

The results of the study extend and support the findings of the prior literature on effectuation and causation. First, the results of the study are in line with the results of the prior entrepreneurship research regarding the use of effectuation, when the decision-making context is uncertain. Sarasvathy (2001) proposed that effectuation is associated with uncertain contexts, while causation relates more to risky contexts. More recently, it has been suggested that effectuation logic becomes more prominent, when uncertainty is present during the first phases of starting a venture, while when uncertainty is absent the entrepreneurs seem to rely on causation (Jiang and Tornikoski, 2019). The findings of this study also suggest that under conditions of perceived uncertainty and novelty in a potential opportunity, experimenter mindset that includes experimentation element from effectuation is the go-to decision-making logic for the entrepreneurs. However, this decision-making logic combined with the context seems to generate disadvantages, since the experimenter mindset is linked to worse profitability compared to competitors. Similarly, the results regarding the degree of novelty of an opportunity differ somewhat from those of the prior literature (Brettel et al., 2012). The results show that both effectuation and causation are connected with perceptions of novelty. Furthermore, the findings of the study extend the prior research by taking into account additional dimensions of the perceived context via a perceived potential entrepreneurial opportunity.

The findings of the study provide evidence that instead of seeing effectuation and causation as opposites, they are complementary in nature. However, conversely to the results of Smolka et al. (2018), who found a positive interaction between experimentation and causation, the results of this study show that affordable loss, flexibility, and pre-commitments and alliances are linked to causation, while experimentation is not. Thus, this further highlights the importance of including perceptions of the conditions under which the individual is making the decisions beyond individual and venture characteristics. Additionally, the results show that better subjective performance is linked to mindsets that combine both causation and 
effectuation, while the mindset that only includes experimentation is connected to worse subjective performance. Thus, this further renders support for the findings of the prior literature than suggest the optimal decision-making approach would be one that combines both causation and effectuation (Welter and Kim, 2018).

The findings of the study contribute to the sustainable entrepreneurship literature by showing that perceived sustainable value creation potential is connected to both effectuation and causation. The results of the prior social entrepreneurship research have indicated that social entrepreneurs use a combination of both causation and effectuation (Corner and Ho, 2010). However, the study also extends findings of the prior research by showing which particular elements, namely the flexibility and affordable loss are linked to a particular type of perceived potential sustainable entrepreneurial opportunity. Furthermore, these results imply that decision-making in the context of potential sustainable entrepreneurial opportunities may differ from the decision-making in the context of other types of potential opportunities. The findings of the study also generate new insight about the performance implications of being sustainable by showing that flexible planner mindset combined with a potential opportunity characterized by innovativeness, uncertainty and sustainable value creation is linked to a perception of better performance than competitors have.

These results have also practical implications. The results suggest that under particular decision-logic combinations are linked to better subjective performance. The findings of the study show that networking planner mindset and flexible planner mindset, which combine both effectuation and causation, are connected to better subjective performance; however, this is only under certain conditions. This implies two important consideration for entrepreneurs. First, combining elements of both decision-making logics may provide better performance outcomes in terms of profitability, but their effectiveness is contingent on the perceived potential opportunity. When uncertainty is moderate, a combination of the logics may provide the best performance outcomes. Conversely, when uncertainty is high, experimentation may be the best option to move forward, since the uncertainty may be so high that making any plans may seem impossible.

The paper has limitations that also open up new avenues for research. First, the paper is limited to the context of Finnish SMEs. Expanding and testing the models in a different context would provide new insights about conditions under which decision-making logics provide benefits to ventures. Second, the paper focused on certain aspects of entrepreneurial cognition, namely decision-making logics and perceptions of entrepreneurial opportunities. Including additional variables, such as motivation, grit or passion, would provide a more complex picture of entrepreneurial cognition. Lastly, the dependent variable in the study was self-reported measure and thus utilizing objective performance measures might provide different insights about the impact of decision-making logics and perceptions on performance. This has been also indicated by the prior literature by showing that the use of objective performance measurement over subjective performance measurement moderates the relationship between planning and performance (Brinckmann et al., 2010). Furthermore, having different aspects of performance besides profitability could provide a further understanding of how effectuation and causation under specific conditions shape performance.

\title{
Appendix A: Results of factor analysis
}

\author{
<INSERT TABLE A.1 ABOUT HERE
}




\section{REFERENCES:}

Arend, R.J., H. Sarooghi, and A. Burkemper (2015), 'Effectuation as ineffectual? Applying the 3E theory-assessment framework to a proposed new theory of Entrepreneurship', Academy of Management Review, 40 (4), 630-651.

Baron, R.A. (2004), 'The cognitive perspective: a valuable tool for answering entrepreneurship's basic "why" questions', Journal of Business Venturing, 19 (2), 221-239.

Baron, R.A. (2006), 'Opportunity recognition as pattern recognition: how entrepreneurs "connect the dots" to identify new business opportunities', Academy of Management Perspectives, 20 (1), 104-119.

Baron, R.A. and M.D. Ensley (2006), 'Opportunity recognition as the detection of meaningful patterns: evidence from comparisons of novice and experienced entrepreneurs', Management Science, 52 (9), 1331-1344.

Baron R.A. and T.B. Ward (2004), 'Expanding entrepreneurial cognition's toolbox: potential contributions from the field of cognitive science', Entrepreneurship: Theory and Practice, 28 (6), 553-573.

Barreto, I. (2012), 'Solving the entrepreneurial puzzle: The role of entrepreneurial interpretation in opportunity formation and related processes', Journal of Management Studies, 49 (2), $356-$ 380.

Brettel, M., R. Mauer, A. Engelen and D. Küpper (2012), 'Corporate effectuation: Entrepreneurial action and its impact on RandD project performance', Journal of Business Venturing, 27 (2), 167-184.

Brinckmann, J., D. Gruchnik, and D. Kapsa, (2010), 'Should entrepreneurs plan or just storm the castle? A meta-analysis on contextual factors impacting the business planning-performance relationship in small firms', Journal of Business Venturing, 25 (1), 24-40.

Chandler, G.N., D.R. DeTienne, A. McKelvie and T.V. Mumford (2011), 'Causation and effectuation processes: A validation study', Journal of Business Venturing, 26 (3), 375-390.

Corner, P.D. and M. Ho (2010), 'How opportunities develop in social entrepreneurship', Entrepreneurship Theory and Practice, 34 (4), 635-659.

Davidsson, P. (2019), 'Opportunities re-conceptualized: Updating the research agenda', Working Paper, assessed 23 January 2019 at www.researchgate.net/profile/PerDavids son/publication/330081102_Opportunities_Reconceptualized_Updating_the_Research_Agenda /links/5c2c6dcda6fdccfc70773517/Opportunities-Re-conceptualized-Updating-the-ResearchAgenda.pdf.

Dean, T.J. and J.S. McMullen (2007), 'Toward a theory of sustainable entrepreneurship: Reducing environmental degradation through entrepreneurial action', Journal of Business Venturing, 22 (1), 50-76.

Dixon-Fowler, H.R., D.J. Slater, J.L. Johnson, A.E. Ellstrand and A.M. Romi (2013), 'Beyond "Does it pay to be green?" A meta-analysis of moderators of the CEP-CFP relationship', Journal of Business Ethics, 112 (2), 353-366. 
Dreiseitl, S. and L. Ohno-Machado (2002), 'Logistic regression and artificial neural network classification models: a methodology review', Journal of Biomedical Informatics, 35 (5-6), 352359.

Gregoire, D.A., J. Cornelissen, D. Dimov and E. van Burg (2015), 'The mind in the middle: Taking stock of affect and cognition research in entrepreneurship', International Journal of Management Reviews, 17 (2), 125-142.

Grimm, R.C. and F.M. Amatucci (2013), 'Effectuation: An alternative approach for developing sustainability architecture in small business', Journal of Small Business Strategy, 23 (1), 55-69.

Gruber, M., S.M. Kim and J. Brinckmann (2015), 'What is an attractive business opportunity? An empirical study of opportunity evaluation decisions by technologists, managers, and entrepreneurs', Strategic Entrepreneurship Journal, 9 (3), 205-225.

Hahn, T., F. Figge, J. Pinkse and L. Preuss (2010), 'Editorial: Trade-offs in corporate sustainability: You can't have your cake and eat it', Business Strategy and the Environment, 19 (4), 217-229.

Hanohov, R. and L. Baldacchino (2018), 'Opportunity recognition in sustainable entrepreneurship: an exploratory study', International Journal of Entrepreneurial Behavior and Research, 24 (2), 333-358.

Haynie, J.M., D.A. Shepherd and J.S. McMullen (2009), 'An opportunity for me? The role of resources in opportunity evaluation decisions', Journal of Management Studies, 46 (3), 337-361.

Hockerts, K. and R. Wüstenhangen (2010), 'Greening Goliaths versus emerging Davids theorizing about the role of incumbents and new entrants in sustainable entrepreneurship', Journal of Business Venturing, 25 (5), 481-492.

Jiang, Y. and E.T. Tornikoski (2019), 'Perceived uncertainty and behavioral logic: Temporality and unanticipated consequences in the new venture creation process', Journal of Business Venturing, 34 (1), 23-40.

Johansson, A., H-K. Ellonen, A. McKelvie and A. Tarkiainen (2015), 'Explaining the coexistence of effectuation and causation', Frontiers of Entrepreneurship Research, 35 (13), 307313.

Kotu, Vijay and Bala Despande (2015), Predictive Analytics and Data Mining, Waltham, MA, USA: Elsevier Inc.

Krueger, N.F. (2007), 'What lies beneath? The experiential essence of entrepreneurial thinking', Entrepreneurship: Theory and Practice, 31 (1), 123-138.

Lerner, D.A., R.A. Hunt and D. Dimov (2018), 'Action! Moving beyond the intendedly-rational logics of entrepreneurship', Journal of Business Venturing, 33 (1), 52-69.

Martin, L. (2015), 'Incorporating values into sustainability decision-making', Journal of Cleaner Production, 105, 146-156.

McMullen, J.S. and D.A. Shepherd (2006), 'Entrepreneurial action and the role of uncertainty in the theory of the entrepreneur', Academy of Management Review, 31 (1), 132-152.

Muñoz, P. (2018), 'A cognitive map of sustainable decision-making in entrepreneurship: $A$ configurational approach', International Journal of Entrepreneurial Behavior and Research, 24 (3), 787-813. 
Muñoz, P. and B. Cohen (2018), 'Sustainable entrepreneurship research: taking stock and looking ahead', Business Strategy and the Environment, 27 (3), 300-322.

Muñoz, P. and D. Dimov (2015), 'The call of the whole in understanding the development of sustainable ventures', Journal Business Venturing, 30 (4), 632-654

Patzelt, H. and D.A. Shepherd (2011), 'Recognizing opportunities for sustainable development', Entrepreneurship Theory and Practice, 35 (4), 631-652.

Porter, M.E. and M.R. Kramer (2011), 'Creating shared value', Harvard Business Review, 89, (1/2), 62-77.

Ramoglou, S. and E.W.K. Tsang (2016), 'A realist perspective of entrepreneurship: Opportunities as propensities', Academy of Management Review, 41 (3), 410-434.

Read, S., M. Song and W. Smit (2009), 'A meta-analytic review of effectuation and venture performance', Journal of Business Venturing, 24 (6), 573-587.

Read, S., S.D. Sarasvathy, N. Dew and R. Wiltbank (2016), 'Response to Arend, Sarooghi, and Burkemper (2015): Cocreating effectual entrepreneurship research', Academy of Management Review, 41(3), 528-556.

Renko, M., R.C. Schrader and M. Simon (2012), 'Perception of entrepreneurial opportunity: a general framework', Management Decision, 50 (7), 1233-1251.

Santos, S.C., A. Caetano, R. Baron and L. Curral (2015), 'Prototype models of opportunity recognition and the decision to launch a new venture', International Journal of Entrepreneurship Behavior and Research, 21 (4), 510-538.

Sarasvathy, S.D. (2001), 'Causation and effectuation: Toward a theoretical shift from economic inevitability to entrepreneurial contingency', Academy of Management Review, 26 (2), 243-263.

Schaltegger, S. and M. Wagner (2011), 'Sustainable entrepreneurship and sustainability innovation: categories and interactions', Business Strategy and the Environment, 20 (4), 222237.

Shepherd, D.A. and H. Patzelt (2011), 'The new field of sustainable entrepreneurship: studying entrepreneurial action linking 'what is to be sustained' with 'what is to be developed", Entrepreneurship Theory and Practice, 35 (1), 137-163.

Shepherd, D.A., H. Patzelt and R.A. Baron (2013), "I Care about nature, but ... .": disengaging values in assessing opportunities that cause harm', Academy of Management Journal, 56 (5), 1251-1273.

Smolka, K.M., I. Verheul, K. Burmeister-Lamp and P.P.M.A.R. Heugens (2018), 'Get it together! Synergistic effects of causal and effectual decision-making logics on venture performance', Entrepreneurship Theory and Practice, 42 (4), 571-604.

Sutter, C., G.D. Bruton and J. Chen (2019), 'Entrepreneurship as a solution to extreme poverty: A review and future research directions', Journal of Business Venturing, 34 (1), 197-214.

Wang, T. and P. Bansal (2012), 'Social responsibility in new ventures: profiting from a long-term orientation', Strategic Management Journal, 33 (10), 1135-1153.

Welter, C. and S. Kim (2018), 'Effectuation under risk and uncertainty: A simulation model', Journal of Business Venturing, 33 (1), 100-116. 
Table 4.1 Descriptive analysis

\begin{tabular}{lccc|ccccccccc}
\hline & Mean & St.d. & Cron & Cau & Exp & AL & Flex & PA & Nov & Eco & Sust & Unc \\
\hline Cau & 3.36 & 0.83 & 0.82 & & & & & & & & & \\
Exp & 2.45 & 1.00 & 0.72 & $-.16^{*}$ & & & & & & & & \\
AL & 3.49 & 1.22 & 0.82 & .06 & -.01 & & & & & & & \\
Flex & 4.11 & 0.74 & 0.65 & .08 & -.07 & $.33^{*}$ & & & & & & \\
PA. & 3.12 & 0.81 & 0.75 & $.35^{*}$ & .05 & -.00 & .10 & & & & & \\
Nov & 2.63 & 1.19 & 0.82 & $.20^{*}$ & .06 & -.07 & -.07 & .13 & & & & \\
Eco & 3.02 & 1.02 & 0.80 & .10 & -.03 & .03 & .07 & -.02 & .10 & & & \\
Sust & 3.09 & 0.89 & 0.77 & $.38^{*}$ & -.12 & .12 & .03 & $.16^{*}$ & $.34^{*}$ & $.17^{*}$ & & \\
Unc & 1.94 & 0.55 & 0.45 & $.31^{*}$ & .00 & $-.19^{*}$ & -.05 & .13 & $.17^{*}$ & .02 & $.21^{*}$ & \\
FP & 2.39 & 0.69 & - & .11 & -.12 & $.15^{*}$ & .10 & .02 & -.04 & .05 & -.04 & -.04 \\
\hline
\end{tabular}

${ }^{*}=p<.05$

** St.d.=standard deviation. Cron=Cronbach's alpha, Cau=causation, Exp=experimentation, $A L=a f f o r d a b l e ~ l o s s$, Flex=flexibility, $\mathrm{PA}=$ precommitments and alliances, $\mathrm{Nov}=$ novelty of an opportunity, Ec0=economic value of an opportunity, Sust=sustainable value of an opportunity, Unc=uncertainty of an opportunity, FP=financial performance

INPUTS

HIDDEN LAYER
OUTPUTS

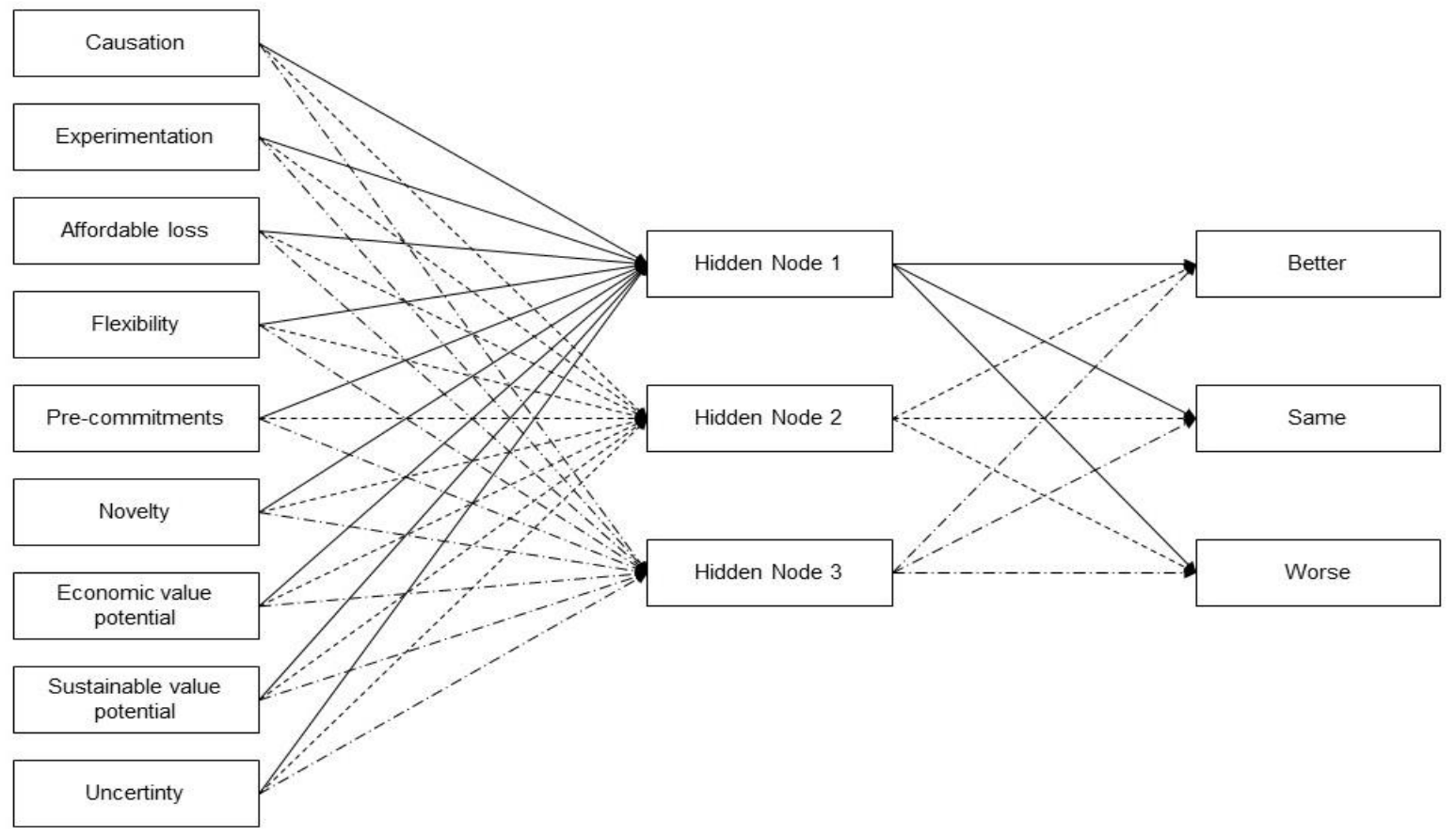

Figure 4.1 Illustration of ANN model 
Table 5.1 Results for ANN

\begin{tabular}{|c|c|c|c|c|}
\hline \multicolumn{5}{|c|}{ Prediction accuracy } \\
\hline & $\begin{array}{l}\text { True } \\
\text { Same }\end{array}$ & $\begin{array}{l}\text { True } \\
\text { Better }\end{array}$ & True Worse & Class precision \\
\hline Predicted Same & 38 & 9 & 37 & $37.33 \%$ \\
\hline Predicted Better & 57 & 14 & 51 & $51.35 \%$ \\
\hline Predicted Worse & 4 & 3 & 27 & $27.27 \%$ \\
\hline $\begin{array}{l}\text { Class recall } \\
\text { Accuracy }\end{array}$ & $\begin{array}{l}38.58 \% \\
44.63 \%\end{array}$ & $\begin{array}{l}57.58 \% \\
7.77 \%)\end{array}$ & $11.54 \%$ & \\
\hline \multicolumn{5}{|c|}{ Effect of input layer factor on hidden layer nodes } \\
\hline & Node 1 & Node 2 & Node 3 & $\begin{array}{c}\text { Total } \\
\text { contribution }\end{array}$ \\
\hline Causation & -2.928 & 5.594 & 4.638 & 7.304 \\
\hline Experimentation & 1.392 & -5.315 & -6.239 & -10.162 \\
\hline Affordable loss & -7.891 & 3.765 & -4.202 & -8.328 \\
\hline Flexibility & -0.385 & 4.845 & 0.420 & 4.880 \\
\hline Pre-commitments & -1.291 & -3.761 & 3.094 & -1.958 \\
\hline Novelty & 3.892 & 5.671 & -1.809 & 7.754 \\
\hline Economic value & 2.425 & -6.111 & 8.618 & 4.932 \\
\hline Sustainable value & -4.875 & 2.054 & -2.938 & -5.759 \\
\hline Uncertainty & 11.529 & 2.916 & -4.918 & 9.527 \\
\hline Bias & -9.805 & -12.368 & -12.525 & -34.698 \\
\hline \multicolumn{5}{|c|}{ Effect of hidden layer nodes on output variable (profitability) } \\
\hline & Better & Same & Worse & $\begin{array}{c}\text { Total } \\
\text { contribution }\end{array}$ \\
\hline Node 1 & -0.816 & -4.664 & 5.419 & -0.061 \\
\hline Node 2 & 2.012 & -1.912 & -5.943 & -5.843 \\
\hline Node 3 & 5.045 & -6.704 & -5.041 & -6.700 \\
\hline Bias & -0.360 & 0.009 & -2.344 & -2.695 \\
\hline
\end{tabular}

Table A. 1 Factor loadings for variables

\begin{tabular}{|c|c|c|c|c|c|}
\hline Causation-effectuation & C & $\mathbf{E}$ & $\mathbf{A L}$ & $\mathbf{F}$ & PA \\
\hline $\begin{array}{l}\text { 1. We analyzed long run opportunities and selected what we } \\
\text { thought would provide the best returns }\end{array}$ & .60 & & & & \\
\hline $\begin{array}{l}\text { 2. We developed a strategy to best take advantage of } \\
\text { resources and capabilities }\end{array}$ & .69 & & & & \\
\hline 3. We designed and planned business strategies & .84 & & & & \\
\hline $\begin{array}{l}\text { 4. We organized and implemented control processes to make } \\
\text { sure we met objectives }\end{array}$ & .71 & & & & \\
\hline $\begin{array}{l}\text { 5. We researched and selected target markets and did } \\
\text { meaningful competitive analysis }\end{array}$ & .71 & & & & \\
\hline
\end{tabular}


6. We had a clear and consistent vision for where we wanted to end up

7. We designed and planned production and marketing efforts $\quad .74$

8. We experimented with different products and/or business models.

9. The product/service that we now provide is essentially the same as originally conceptualized. *

10. The product/service that we now provide is substantially different than we first imagined.

11. We tried a number of different approaches until we found a business model that worked.

12. We were careful not to commit more resources than we could afford to lose.

13. We were careful not to risk more money than we were willing to lose with our initial idea.

14. We were careful not to risk so much money that the company would be in real trouble financially if things did not work out.

15. We allowed the business to evolve as opportunities emerged.

17. We were flexible and took advantage of opportunities as they arose.

18. We avoided courses of action that restricted our flexibility and adaptability

19. We used a substantial number of agreements with customers, suppliers and other organizations and people to reduce the amount of uncertainty.

20. We used pre-commitments from customers and suppliers as often as possible.

21. Network contacts provided low cost resources.

22. By working closely with people/organizations external to our organization, we have been able to greatly expand our capabilities.

23. We have focused on developing alliances with other people and organizations.

24. Our partnerships with outside organizations and people play a key role in our ability to provide our product/service.

\begin{tabular}{|c|c|c|c|c|}
\hline Entrepreneurial opportunity & $\mathbf{N}$ & $\mathbf{E}$ & $\mathbf{S}$ & $\mathbf{U}$ \\
\hline 1. Our venture represents the most innovative idea & .79 & & & \\
\hline 9. There is no similar way of doing business anywhere & .87 & & & \\
\hline
\end{tabular}


17. Our business idea is new and original

3. The venture would provide me with nice profit

11. I can make a living with the income from the venture

19. With the help of the venture, I am able to generate wealth for myself in the future

22. The venture would generate economic added value

4. We would contribute to solving social problems

6 . The venture operates in an environmentally-friendly way

12. The venture helps to improve the state of the environment for its part

14. Social responsibility is self-evident to us

20. We would generate societal added value that cannot be measured in monetary terms

23. Our business idea enhances sustainable development

2. In order to start the venture, we would have to invest in it considerable resources

5. The opportunity would have passed us soon if would not have exploited it

10. This business would have a considerably high risk of failure
.90

.81

\footnotetext{
*Items were originally in Finnish, $\mathrm{C}=$ causation, $\mathrm{E}=$ experiments, $\mathrm{AL}=$ affordable loss, $\mathrm{F}=$ flexibility, $\mathrm{PA}=$ pre-commitments and alliances, $\mathrm{N}=$ the degree of novelty in an opportunity, $\mathrm{E}=$ the degree of economic value in an opportunity, $S=$ the degree of sustainable value in an opportunity, $U=$ the degree of uncertainty in an opportunity
} 